\title{
Molecular Cloning and Preliminary Characterization of a Novel Cytoplasmic Antigen Recognized by Myasthenia Gravis Sera
}

Tom Gordon, Bryon Grove, Joseph C. Loftus, ${ }^{*}$ Tim O'Toole, ${ }^{*}$ Robert McMillan, ${ }^{\star}$ Jon Lindstrom, ${ }^{\mathbf{5}}$ and Mark H. Ginsberg

${ }^{*}$ Committee on Vascular Biology, ${ }^{\ddagger}$ Department of Basic and Clinical Research, Research Institute of Scripps Clinic,

La Jolla, California 92037; and ${ }^{\S}$ Salk Institute for Biological Studies, La Jolla, California 92037

\begin{abstract}
A cDNA clone was isolated by screening of a $\lambda$ gt1 1 endothelial expression library with serum from a patient with myasthenia gravis (MG). Rabbit antisera raised against the recombinant protein and human MG sera reactive with the clone immunoblotted an $M_{\mathrm{r}} \sim 250,000$ polypeptide (gravin) present in endothelial cells and several adherent cells. Gravin was not detected in platelets, leukocytes, U937, or human erythroleukemic (HEL) cell lines, but was expressed in HEL cells after induction with phorbol myristate acetate. Northern blot analysis showed two transcripts of $\sim 6.7$ and $8.4 \mathrm{~kb}$ in endothelial cells but not U937 or HEL cells. Indirect immunofluorescence of permeabilized cells revealed a trabecular network of gravin staining with a distinct linear component. Antibodies to gravin were present in sera from $22: 72(31 \%)$ of MG patients. In contrast 0:50 normal sera and 1:72 sera from patients with other autoimmune diseases contained antigravin antibodies. Gravin is not likely to be a nonerythroid spectrin, talin, myosin, or actin-binding protein based on the lack of reactivity of antigravin with these polypeptides in immunoblots. The nucleotide sequence of the immunoreactive clone indicated that it encodes a highly acidic polypeptide fragment that contains the carboxyl terminus of the protein. Neither amino acid nor nucleotide sequences were present in Genbank, EMBL, or Swissprot databases as of March, 1992. These data indicate that gravin is an inducible, cell type-specific cytoplasmic protein and that autoantibodies to gravin may be highly specific for MG. ( J. Clin. Invest. 1992.90:992-999.) Key words: myasthenia gravis • autoimmunity • cell adhesion • molecular cloning • gravin
\end{abstract}

\section{Introduction}

Myasthenia gravis (MG) ${ }^{1}$ is a disease of neuromuscular transmission generally believed to be due to autoantibodies to the nicotinic acetylcholine receptor (1). In addition, myasthenics

Address correspondence to Mark Ginsberg, M. D., The Scripps Research Institute, 10666 N. Torrey Pines, La Jolla, CA 92037. Dr. Gordon's present address is Department of Clinical Immunology, Flinders Medical Centre, Bedford Park, South Australia 5042.

Received for publication 29 November 1988 and in revised form 5 May 1992.

1. Abbreviations used in this paper: HEL, human erythroleukemic; HUVE, human umbilical vein endothelial; IPTG, isopropylthioglucose; MG, myasthenia gravis.

J. Clin. Invest.

(C) The American Society for Clinical Investigation, Inc.

$0021-9738 / 92 / 09 / 0992 / 08 \$ 2.00$

Volume 90, September 1992, 992-999 also frequently form antibodies which react with striational muscle antigens (2-4), due to recognition of cytoskeletal elements such as alpha actinin, actin, filamin, and vinculin $(5,6)$. Such cortical cytoskeletal elements localize (7) with acetylcholine receptors at motor endplates, and may be physically linked to the receptors. Since many regions of the acetylcholine receptor are antigenic targets for myasthenic sera (1), it is unlikely that such antibodies arise by "molecular mimicry" (8), i.e., that a restricted antigenic site on the receptor cross-reacts with an exogenous antigen. At present, the alternative hypothesis, that the response to the receptor is "antigen driven", is therefore favored (1). Thus, the autoantibodies present in myasthenic sera may serve to identify intracellular components that may link to transmembrane proteins.

Isolation of $\mathrm{cDNA}$ clones through their expressed antigenic sites (9-13) has been extensively used to isolate clones coding for autoantigens. This approach also offers the possibility of identifying and characterizing novel autoantigens that may be of low abundance and restricted cellular distribution (14). Such proteins may escape detection by more routine screening tests such as immunofluorescence and immunoprecipitation. We have used this approach to isolate cDNA clones that code for an apparently novel cytoplasmic antigen recognized by sera of some patients with MG. This antigen is present in a $250-\mathrm{kD}$ cytoplasmic protein whose cellular distribution suggests that it is a component of the cortical cytoskeleton $(15,16)$. Finally, the protein bearing this antigen and its $\mathrm{mRNA}$ are expressed in a cell type-specific and regulatable fashion by cells in culture.

\section{Methods}

Screening of cDNA library and protein blotting. Recombinant phage from a $\lambda \mathrm{gt} 11$ human umbilical vein endothelial cDNA library (17) (generously provided by J. Evan Sadler, Washington University, St. Louis, MO) were plated on Escherichia coli strain Y1090, overlaid with nitrocellulose filters (Millipore Corp., Bedford, MA), saturated with $10 \mathrm{mM}$ isopropylthioglucose (IPTG) (Sigma Chemical Co., St. Louis, MO), and screened as described (18) with serum from a patient (1) with autoantibodies to both platelet glycoprotein IIIa and to the acetylcholine receptor (19). She is a 47-yr-old white woman with refractory idiopathic thrombocytopaenic purpura of $16 \mathrm{yr}$ duration and mild, generalized MG (Osserman class IIA) since 1981. Rheumatoid factor, antinuclear antibodies, antiparietal cell, antithyroid and antiadrenal antibodies have not been detected. Her serum has also been negative for autoantibodies to dsDNA, RNP, SM, Ro, and La.

Bacterial lysates prepared from E. coli strain Y1089/phage lysogens induced with IPTG as described (18) were resolved on SDS polyacrylamide gels (20) and reactivity of the beta-galactosidase-cDNA fusion protein with human sera and rabbit antisera determined by immunoblotting nitrocellulose transfers (18). Human $\gamma$ and $\mu$ chain-specific biotinylated second antibodies were used to determine the immunoglobulin class (Vector Laboratories, Inc., Burlingame, CA). Cells $\left(10^{7}-10^{8}\right)$ were washed three times in $0.01 \mathrm{M}$ phosphate buffered, 0.15 
M saline, pH 7.4 (PBS), and lysed at ambient temperature in 1\% Triton X-100 containing EDTA $(10 \mathrm{mM})$ benzamidine $(10 \mu \mathrm{g} / \mathrm{ml})$ and Trasylol $(100 \mathrm{U} / \mathrm{ml})$. After centrifugation $(16,000 \mathrm{~g}, 30 \mathrm{~min}$ ) supernatants were mixed with an equal volume of reducing sample buffer before resolution on SDS polyacrylamide gels (10), electrophoretic transfer to nitrocellulose paper, and immunoblotting (18).

Immunofluorescence. GM1380 or MG63 cells grown on fibronectin $(10 \mu \mathrm{g} / \mathrm{ml})$-coated glass slides were fixed with $2 \%$ formaldehyde or fixed and permeabilized with $0.005 \%$ digitonin in $2 \%$ formaldehyde for $5 \mathrm{~min}$ at room temperature. The cells were incubated for $20 \mathrm{~min}$ with a 1:100 dilution of rabbit anti- $\lambda 15$ or anti- $\lambda 15$ absorbed with $\lambda 15$ fusion protein and stained for $30 \mathrm{~min}$ with fluorescein-conjugated goat antirabbit IgG (Cappel Laboratories, Cochranville, PA). Cells were viewed and photographed with a Nikon Optiphot microscope.

DNA sequencing and sequence analysis. Recombinant phage from clone $\lambda 15$ were subcloned into Bluescript KS M13+ (Stratagene Inc., San Diego, CA). Nested deletions were constructed using Bal 31 exonuclease (21) and the sequence of single-stranded DNA determined by the method of Sanger et al. (22) using modified $T_{7}$ DNA polymerase (23). DNA sequences and amino acid sequences were analyzed with the University of Wisconsin Genetics Computer Group Sequence Analysis Software Package (24).

Rabbit polyclonal antibodies. The $180-\mathrm{kD} \beta$-galactosidase-cDNA fusion protein from clone $\lambda 15$ was electroeluted from a $7 \%$ preparative polyacrylamide gel and used to immunize New Zealand White rabbits. The animals were immunized biweekly with $20 \mu \mathrm{g}$ of the fusion polypeptide emulsified in CFA for the first dose and incomplete adjuvant in succeeding immunizations. Reactivity with the $\beta$-galactosidase moiety was removed by absorption with wild type $\lambda$ gt 11 as described below. Sera from the rabbit with the highest antibody titre ( $1 / 12,800$ on nitrocellulose phage plaque lifts of 15 ) was used. Anti- $\lambda 15$ was affinity purified using fusion polypeptides bound to nitrocellulose as described (25). Reactivity against the $\lambda 15$ fusion polypeptide was removed by absorbing antisera with nitrocellulose plaque lifts plated at a density of 50,000 plaque forming units $\lambda 15 / \mathrm{cm}$ plate. Antisera absorbed with wild type $\lambda g t 11$ plaque lifts retained reactivity with $\lambda 15$ fusion protein.

Materials. Restriction enzymes and T4 DNA ligase were purchased from Bethesda Research Laboratories (Gaithersburg, MD) or New England Biolabs (Beverly, MA). Polyclonal antibodies against human platelet actin-binding protein and chicken fodrin were generously provided by Joan Fox (Gladstone Foundation, San Francisco, CA) and J. Glenney (Salk Institute, La Jolla, CA), respectively. Sera from normal blood donors and a variety of autoimmune sera were generously provided by $E$. Tan, $R$. McPherson, and $E$. Tucker of this institution and from the Rheumatology Unit, Flinders Medical Centre. Myasthenic sera were generously provided by M. Seybold (Scripps Clinic, La Jolla, CA).

Cell isolation and cell lines. Human platelets were isolated from acid citrate dextrose anticoagulated human blood by differential centrifugation followed by gel filtration (26). Neutrophils were collected from freshly drawn venous blood by the method of Henson and Oades (27). PBMC were isolated from heparinized blood by centrifugation through Ficoll Hypaque (28). Primary culture human umbilical vein endothelial cells (HUVE) were isolated and grown to confluence on $75-\mathrm{cm}^{2}$ tissue culture flasks (29) and human promyeloid leukemic cell line U936 were cultured as described (30). 4B-Phorbol 12-myristate 13-acetate (PMA) at $100 \mathrm{nM}$ was used to stimulate human erythroleukemic (HEL) cells. Cultured human smooth muscle cells were generously provided by Dr. Walter Laug (University of Southern California Medical Center, Los Angeles), and human osteosarcoma (MG-63) cells were a gift from M. Pierschbacher (La Jolla Cancer Research Foundation).

Northern blot analysis. Total cellular RNA was extracted from endothelial, HEL, and U937 cells by the guanidine isothiocyanate-cesium chloride method, electrophoresed on $1 \%$ agarose formaldehyde gels, and transferred to nylon membrane (Biotrans; ICN Biochemicals, Cleveland, $\mathrm{OH}$ ) (31). Blots were hybridized with a radiolabeled RNA probe constructed with T3 RNA polymerase after subcloning the $\lambda 15 \mathrm{cDNA}$ insert into bluescript M13 and linearizing with BamHI. Final wash was in $0.1 \times$ standard saline citrate (SSC) at $65^{\circ} \mathrm{C}$.

Recombinant antigen ELISA for detection of antigravin antibodies. The $\lambda 15$ insert was subcloned into the pQE-10 vector (Qiagen, Chatsworth, CA) and expressed as an in-frame fusion protein with six histidines at the $\mathrm{NH}_{2}$ terminus. Recombinant protein was purified under nondenaturing conditions by nickel chelate affinity chromatography using a pH 8-5 gradient (32). Microwell ELISA plates (Nunc, Roskilde, Denmark) were coated with $150 \mu \mathrm{l}$ of purified recombinant protein at a concentration of $5 \mu \mathrm{g} / \mathrm{ml}$ in $0.03 \mathrm{M}$ sodium carbonate, $\mathrm{pH} 9.6$ at $4^{\circ} \mathrm{C}$ overnight, followed by blocking for $2 \mathrm{~h}$ with $3 \%$ BSA in PBS. The wells were then incubated for $90 \mathrm{~min}$ at $37^{\circ} \mathrm{C}$ with $0.1 \mathrm{ml}$ duplicate serum samples diluted 1:250 which were preabsorbed with $E$. coli extract (Promega Corp., Madison, WI) to reduce background, washed four times with PBS- $0.05 \%$ Tween 20 , and incubated with $0.1 \mathrm{ml}$ of a 1:1,000 anti-human IgG (Sigma Chemical Co., St. Louis, MO) for $2 \mathrm{~h}$ at $37^{\circ} \mathrm{C}$. After four washes with PBS-Tween $0.1 \mathrm{ml}$ of substrate (disodium $p$-nitrophenyl phosphate, Sigma Chemical Co.) dissolved in diethanolamine buffer ( $\mathrm{pH} 9.8$ ) was added to each well and the $\mathrm{OD}$ at $405 \mathrm{~nm}$ monitored using an ELISA plate reader (MR 600; Dynatech Laboratories, Inc., Chantilly, VA). The rabbit anti- $\lambda 15$ antiserum was used as a positive control in each experiment and the plates read when a $1: 2,000$ dilution reached an OD of $\sim 1.8$. OD values greater than the mean +3 SD from 50 normal controls were considered positive.

\section{Results}

Isolation of cDNA clones coding for epitopes recognized by an $M G$ serum. We isolated initial clones by screening a $\lambda \mathrm{gt} 11 \mathrm{ex}-$ pression library constructed with cDNA complementary to mRNA isolated from cultured HUVE (17) with serum from patient 1 . Initial screening of 500,000 recombinants yielded 10 immunoreactive clones. These clones did not react with polyclonal anti-GPIIb-IIIa antisera (30), rabbit polyclonal antibody to the acetylcholine receptor, or with a panel of 25 sera from patients with chronic idiopathic thrombocytopaenic purpura. In addition, reactivity of the patient's serum with the fusion polypeptides remained after absorption with whole platelets, platelet membranes, and purified GPIIb-IIIa (not shown). This suggested that these cDNAs did not encode epitopes shared with platelet membrane proteins or the acetylcholine receptor. Antibodies affinity-purified from the patient's serum using the protein (25) from one clone containing a $2.0-\mathrm{kb}$ insert, designated $\lambda 15$, cross-reacted with 5:9 of the remaining cDNA clones. None of the cross-reactive clones reacted with pooled human IgG nor did 2:4 of the non-cross-reactive clones. The two clones reactive with pooled normal human IgG were not evaluated further. Sera obtained on three occasions between 1985 and 1987 from patient 1 were reactive with the $\lambda 15$ fusion protein on immunoblots as were multiple serum samples from a second patient with MG (2). A ${ }^{32}$ P-labeled RNA probe constructed with T3 RNA polymerase from the $\lambda 15 \mathrm{cDNA}$ after subcloning into Bluescript M13 cross-hybridized only with the immunologically related clones, indicating that the six clones shared overlapping cDNA sequence. On Western blotting, a single polypeptide of apparent $M_{\mathrm{r}}$ $=180,000$ present in extracts of $E$. coli Y 1089 infected (9) with phage bearing the $\lambda 15$ insert, but not wild type phage, reacted with the patient's serum (Fig. 1). This polypeptide reacted with anti- $\beta$-galactosidase antibodies and was induced with IPTG (not shown), indicating that the $\lambda 15 \mathrm{cDNA}$ contained a long open reading frame in frame with the lac $Z$ reading frame; the predicted size of the insert-coded polypeptide was thus $60 \mathrm{kD}$. 


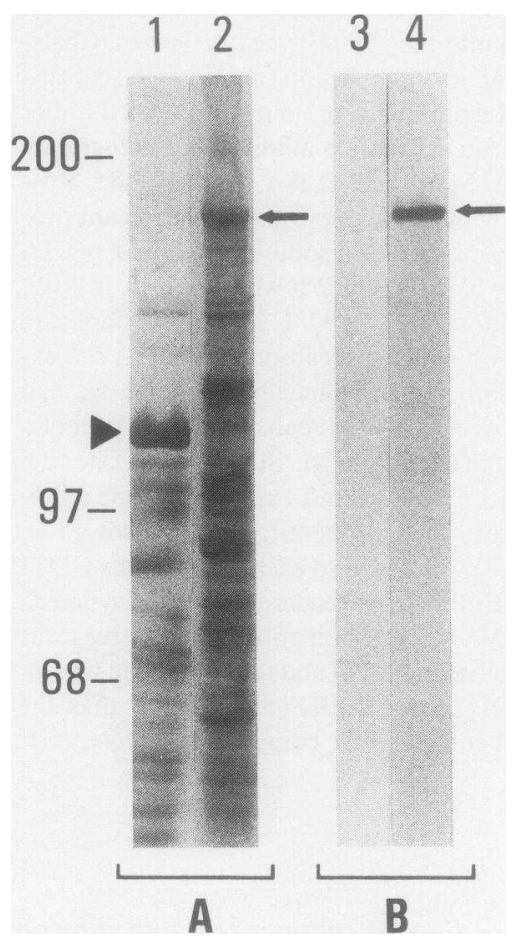

Figure 1. Characterization of the $\lambda 15$ fusion protein. E. coli Y1089 infected with either wild type $\lambda$ gt 11 (lanes 1 and 3 ) or $\lambda 15$ (lanes 2 and 4 ) were induced with isopropylthioglucose and analyzed by $7.5 \%$ SDS-PAGE under reducing conditions. The resultant gels were stained with Coomassie blue (lanes $I$ and 2) or electrophoretically transferred and probed with a patient serum (lanes 3 and 4 ). Note the presence of $\beta$-galactosidase at $M_{\mathrm{r}} 116,000$ in lane 1 which is not reactive with patient serum, lane 3. In lane 2 , note the absence of $\beta$ galactosidase and appearance of a novel band at $M_{\mathrm{r}} 180,000$ which is reactive with patient serum.

Cell-type-specific expression of gravin and gravin mRNA. Rabbit polyclonal antibodies against the $\lambda 15$ fusion polypeptide were prepared and used to characterize the cDNA-encoded protein. Rabbit polyclonal anti- $\lambda 15$ immunoblotted an apparent $M_{\mathrm{r}} 250,000$ protein (designated gravin) in extracts of several preparations of primary cultures of HUVE on reduced and nonreduced SDS gels. Faint bands of lower molecular weight were seen on some blots and were presumed to be proteolytic fragments. Reactivity with the $250-\mathrm{kD}$ band was blocked by absorption of polyclonal serum with the $\lambda 15$ fusion protein and not observed with preimmune rabbit serum (Fig. 2). Gravin was not detected in the spent culture media (not shown). Both prototype myasthenic sera (\#1 and \#2) also reacted with the $250-\mathrm{kD}$ endothelial protein on immunoblots, confirming that the reactivity of patient sera with the insert-coded polypeptide was associated with reactivity with an endothelial cell protein which shared epitopes with the polypeptide encoded by $\lambda 15$ (Fig. 2). The $\lambda 15$ insert hybridized with two mRNA species from HUVE on Northern blots (Fig. 3). The size of these species $(\sim 6.7$ and $8.4 \mathrm{~kb})$ could encode a polypeptide of the size of gravin. No mRNA hybridizing with $\lambda 15$ was detected in blots from two cell lines which grow in suspension, HEL and U937, suggesting that expression of this protein might be celltype-specific. To explore this possibility, Western blots of a variety of cultured cell extracts were probed with the anti- $\lambda 15$ (Fig. 4).

Anti- $\lambda 15$ reacted with the $250-\mathrm{kD}$ protein in extracts of several adherent cultured cells including fibroblasts (GM1380), osteosarcoma cells (MG63), smooth muscle cells, as well as HUVE. In contrast, a variety of nonadherent cultured cells and peripheral blood cells did not react with this antibody. Most notably, the two cell lines that did not express mRNA hybridizing with the $\lambda 15$ probe did not express gravin.

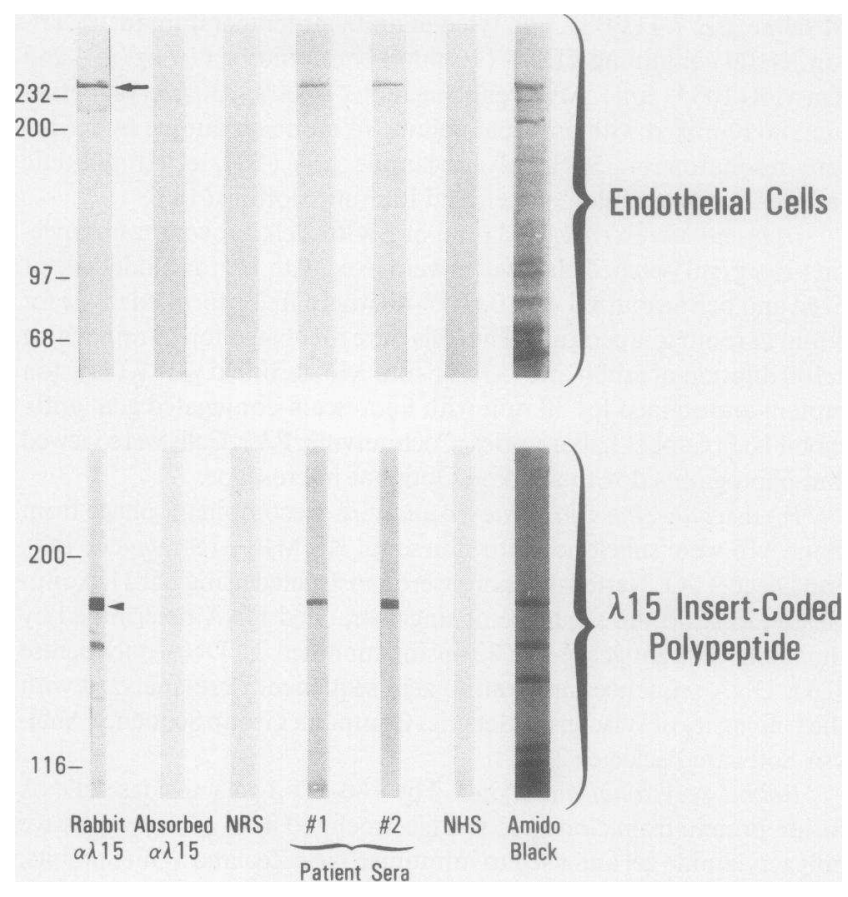

Figure 2. Reactivity of patient serum and polyclonal rabbit anti- $\lambda 15$ antibodies with endothelial cells and fusion protein. Western transfers of endothelial cells or $E$. coli $Y 1089$ infected with $\lambda 15$ were separated by 6 or $7.5 \%$ SDS-PAGE, respectively, and probed with the indicated antibodies. Note in the endothelial cell the reactivity of anti- $\lambda 15$ with a $250-\mathrm{kD}$ band which is also recognized by sera from myasthenic patients $(\# 1, \# 2)$. Note the absence of reactivity with anti- $\lambda 15$ preabsorbed with the insert-coded polypeptide and lack of reactivity with normal rabbit serum $(N R S)$ and normal human serum $(N H S)$. Note the similar patterns of reactivity with the $\lambda 15$ insert-coded polypeptide.

This result, coupled with the fact that the 8.4-kb mRNA could readily accommodate the coding sequence for gravin, indicates that the $\lambda 15$ insert encodes a fragment of gravin. Finally, cul-
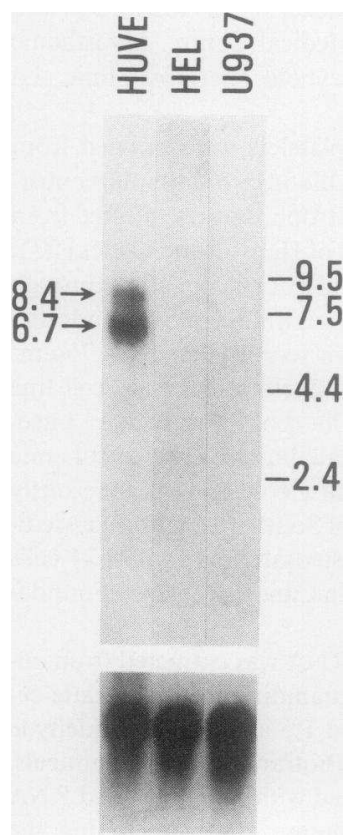

Figure 3. Northern blot analysis. $10 \mu \mathrm{g}$ of total RNA from human umbilical vein endothelial cells, human erythroleukemia cells, or U937 cells were separated and probed with the $\lambda 15$ insert. Note that two species, 8.4 and $6.7 \mathrm{~kb}$, hybridize with this insert. Below are shown the signals obtained with each of the blots when they were reacted with an actin probe. 


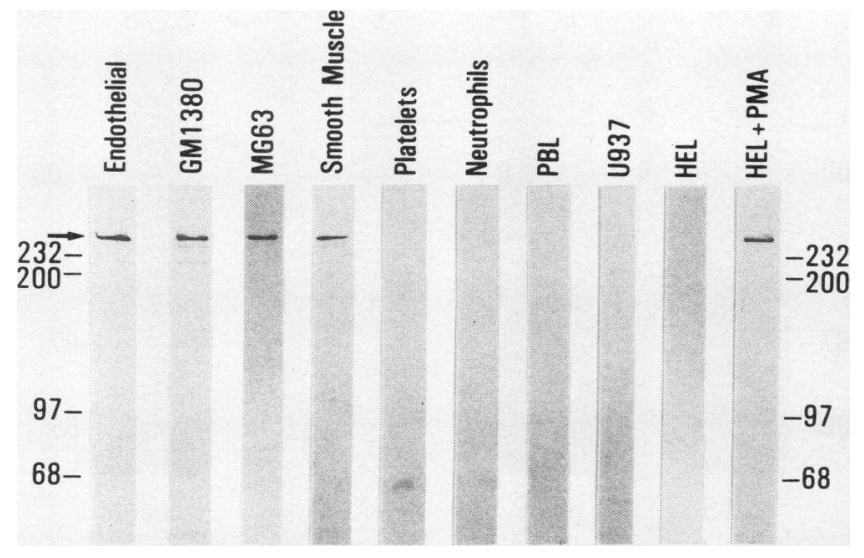

Figure 4. Western blotting detection of gravin in a variety of cells. Extracts of cultured endothelial cells, GM1380 (fibroblasts), MG63 (osteosarcoma cells), smooth muscle cells, U937, and human erythroleukemia cells (HEL) were separated by $7.5 \%$ SDS-PAGE, and Western transfers were probed with a polyclonal antibody to $\lambda 15$. Note the prominent band at $M_{\mathrm{r}} \sim 250,000$ in the endothelial cells, GM1380, MG63, and smooth muscle cells. Note the absence of staining in all cells isolated from peripheral blood and in the U937 and HEL cells. Note the presence of staining in HEL cells cultured in the presence of phorbol myristate acetate.

ture of the HEL cells in the presence of phorbol myristate acetate for $48 \mathrm{~h}$ was associated with expression of gravin. These cells also adhered to the culture dish, consistent with the development of a macrophage phenotype (33). We also used the antibody to the insert-coded polypeptide to evaluate the intracellular distribution of gravin.

Intracellular localization of gravin. The anti- $\lambda 15$ did not stain intact cells or their matrix (staining with antifibronectin confirmed the presence of the matrix [ not shown]), suggesting that the polypeptide segment encoded by $\lambda 15$ was not accessible on the cell surface. In contrast, permeabilized cells were brightly stained with the antibody, but not by preimmune serum or absorbed anti- $\lambda 15$ (Fig. 5). The staining pattern was that of a meshwork throughout the cytosol, and extending right to the edge of the cell, and into ruffles and filopodia. In some cells the staining had a linear component orientated along the long axis of the cell. There was no staining of the nucleus, nor of microtubules or of focal contacts (the presence of the latter two was confirmed by staining for tubulin and talin, respectively). This meshwork staining of the cortical cytoplasm suggested that gravin might be a spectrin or a filamin, two proteins of similar size which yield similar staining patterns $(34,35)$. This possibility was evaluated by comparison of the proteins recognized by antibodies against each of these species with those recognized by anti- $\lambda 15$ (see below).

Detection of antigravin antibodies in patients with $M G$ and other autoimmune diseases by recombinant antigen ELISA. IgG autoantibodies to the recombinant gravin fragment were identified in 22:72 $(31 \%)$ of MG sera and in 1:17 patients with rheumatoid arthritis ( $>$ mean $+3 \mathrm{SD}$ of 50 normal sera $=0.26$ OD units). No reactivity was observed with normals or with sera from patients with systemic lupus erythematosus, progressive systemic sclerosis, chronic active hepatitis, and polymyositis (Fig. 6). Within this group were patients with known reactivities to the Ro, La, RNP, Sm, centromere, Scl-70, dsDNA, histone, and proliferating cell nuclear antigens. Prototype
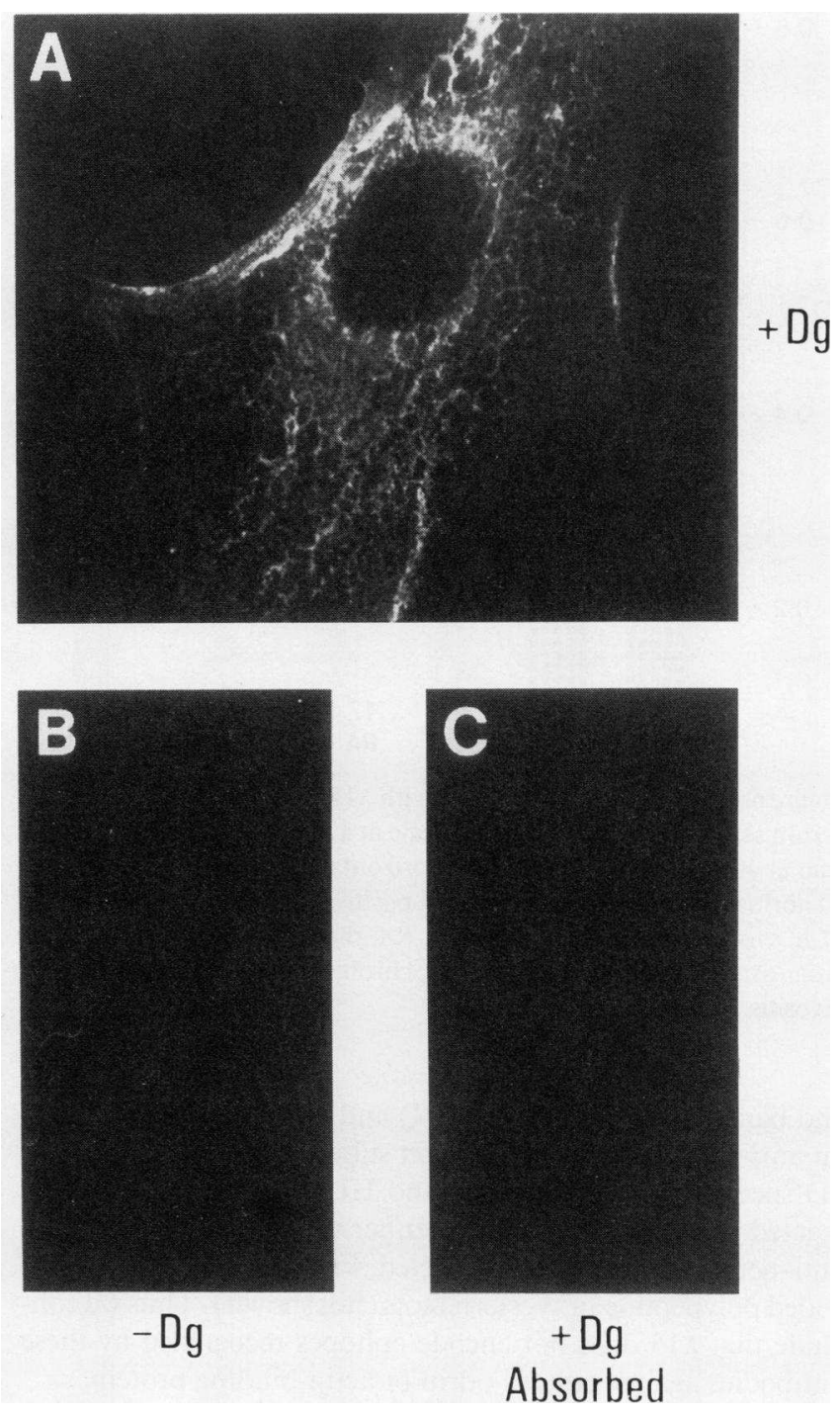

Figure 5. Immunofluorescent localization of gravin. Affinity-purified anti- $\lambda 15$ antibody was used to stain detergent permeabilized cells $(A)$ or intact cells $(B)$. $C$ shows staining of permeabilized cells with anti- $\lambda 15$ which had been preabsorbed with the insert coded polypeptide (see Fig. 2). In the permeable cells note the meshwork staining which extends all the way to the cell periphery and into ruffles and filopodia. Note the absence of staining of microtubules, and absence of staining of focal contacts. Note the absence of staining in intact cells suggesting that the polypeptide segment recognized by this antibody is not accessible on the cell surface.

myasthenic sera \#1 and \#2 gave positive ELISA values of 0.48 and $1.60 \mathrm{OD}$ units, respectively. Levels of antigravin antibodies did not correlate with serum anti-acetylcholine receptor antibody titers (data not shown). Data from this survey demonstrate that antigravin antibodies may be relatively specific for MG.

Lack of immunological identity of gravin with fodrin or actin-binding protein. As previously noted, anti- $\lambda 15$ reacted with gravin in endothelial cells but did not react with platelets. In contrast, an antibody to actin-binding protein reacted with an apparent $M_{\mathrm{r}} 250$ polypeptide from platelets and HUVE (Fig. 7). The lack of reactivity of anti- $\lambda 15$ with platelets is also noteworthy since these cells are rich in myosin, alpha actinin, actin-binding protein, vinculin (36), and contain a spectrin 


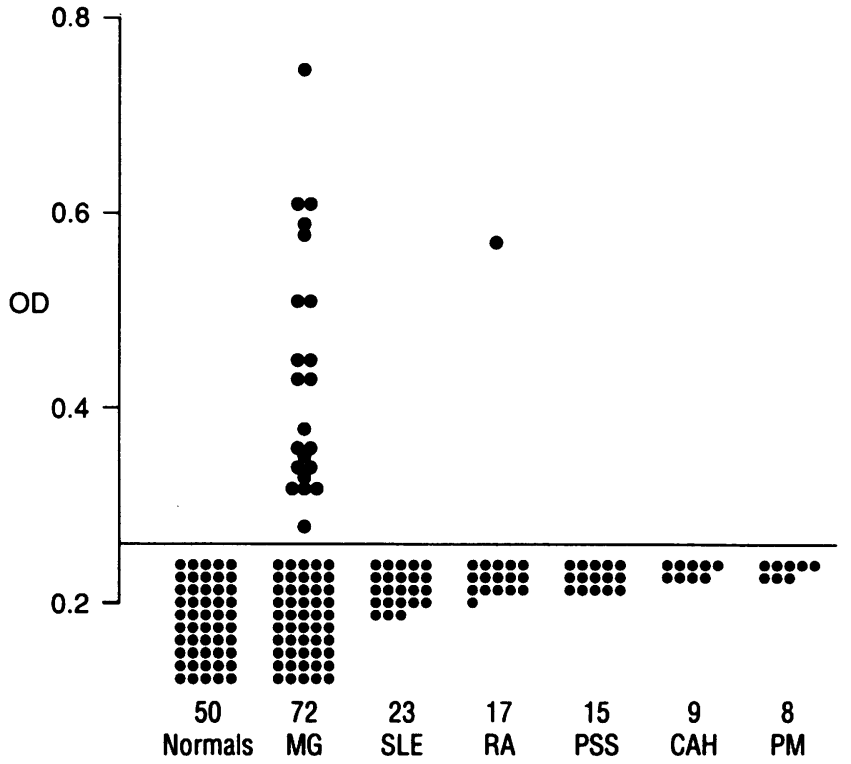

Figure 6. Reactivity of human sera with $\lambda 15$ fusion protein by ELISA. Serum samples were tested in duplicate at a 1:250 dilution and OD read at $405 \mathrm{~nm}$. Values above the horizontal line (mean $+3 \mathrm{SD}$ from 50 normal subjects) were considered positive. $M G$, myasthenia gravis; $S L E$, systemic lupus erythematosus; $R A$, rheumatoid arthritis; $P S S$, progressive systemic sclerosis; $C A H$, chronic active hepatitis; $P M$, polymyositis.

and band 4.1-related species (37) and talin (38). In addition, an anti-chicken Fodrin common subunit reacted with a 235 . $\mathrm{kD}$ species from brain cortex and HUVE, whereas anti- $\lambda 15$ reacted with neither. Finally, neither the anti-Fodrin, nor the anti-actin-binding protein reacted with the expressed insert coded polypeptide in Western blots (not shown). Thus we conclude that $\lambda 15$ does not encode epitopes recognized by these antibodies against either Fodrin or actin-binding protein.

Nucleotide and predicted peptide sequence of the $\lambda 15$ insert. The determined nucleotide and predicted peptide sequence of the $\lambda 15$ insert appear in Fig. 8. The insert contains 1,993 bases terminating with the polyadenylation signal followed 15 bases downstream by 12 adenines, indicating that the insert is complementary to the $3^{\prime}$ end of the mRNA. A long open reading frame, in frame with the linkers used in library construction (17), coded for a 306 residue peptide which terminated with a TAA stop condon at nucleotide 920 and contained no predicted sites for Asn-linked oligosaccharides. The predicted molecular mass for this peptide was $33,056 \mathrm{D}$ and it was moderately hydrophilic and strongly acidic, with a predicted net charge of -48 . The predominant (39) predicted secondary structure within the peptide was alpha helix and numerous continuous antigenic sites were predicted by the algorithm of Jameson and Wolf (40). Searches of Genbank and EMBL nucleic acid databases and NBRF protein databases (as of March, 1992 ) with the Wordsearch program did not reveal significant sequence identities. There was a weak similarity at the protein level to the carboxy terminus of the pig neurofilament triplet $\mathrm{L}$ protein (41), and the similarity was judged significant using the Relate (42) program (segment length $=17$, segment comparison score $=4.4$. SD units)

Based on the measured apparent $M_{\mathrm{r}}$ of the fusion protein we had anticipated an insert-coded polypeptide of $M_{\mathrm{r}} 60,000$,

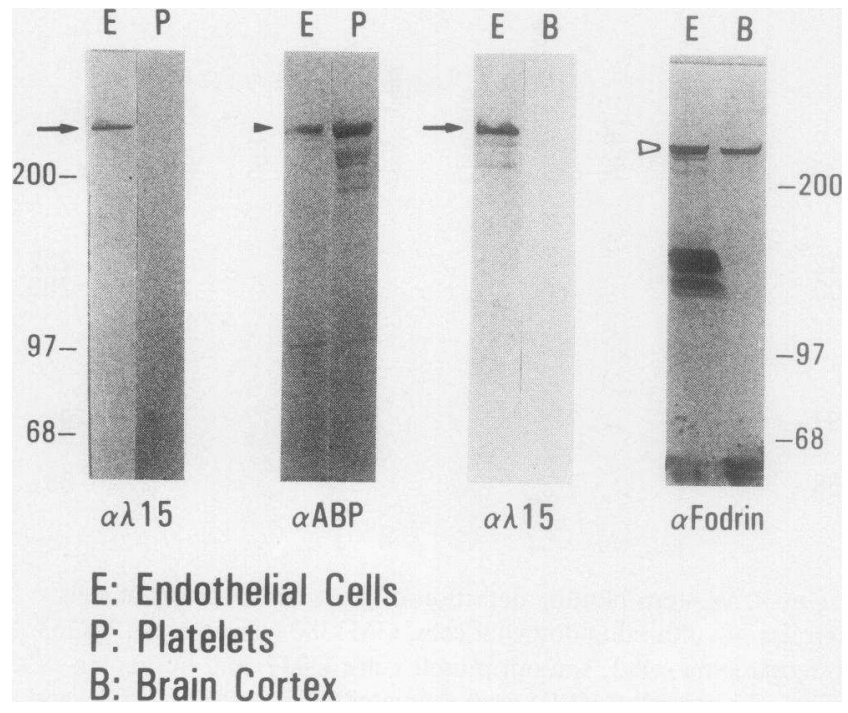

Figure 7. Immunochemical comparison of gravin with actin binding protein $(A B P)$ and Fodrin. Extracts of endothelial cells, platelets, or brain were analyzed by $7.5 \%$ SDS polyacrylamide gel electrophoresis and Western transfers were probed with polyclonal antibodies to $\lambda 15$, polyclonal antibodies to ABP, or an anti-chicken Fodrin common subunit antibody. In the first pair of lanes note the reactivity of gravin with anti- $\lambda 15$ in endothelial cells and the absence of reactivity in platelets. In the companion lane note the reactivity of $\mathrm{ABP}$ in platelets with anti-ABP. In the next two sets of lanes note the reactivity of the anti-Fodrin antibody with an $M_{\mathrm{r}} \sim 235,000$ species in endothelial cells and brain cortex and the absence of such reactivity in the case of anti- $\lambda 15$.

rather than the actual predicted size of $33 \mathrm{kD}$. It should be noted that following nucleotide 920 there were multiple stop codons in all three reading frames. Moreover, previous work has drawn attention to the aberrant migration of highly acidic fusion proteins (10) in SDS-PAGE, suggesting this as an alternative explanation for this finding. To test this possibility we deleted 917 bases of the predicted 3' untranslated region starting at the XbaI site at nucleotide 1070 and verified the extent of deletion by sequence analysis. The intact insert and the 1076 nucleotide deletion fragment were then both expressed in Bluescript M13 under control of the lac promoter. Both inserts coded for polypeptides of identical apparent $M_{\mathrm{r}} 65,000$ (Fig. 9), indicating that translation terminates within $150 \mathrm{bp}$ of nucleotide 920 to produce a fusion protein that migrates aberrantly on SDS-PAGE.

\section{Discussion}

In this work, serum from a patient with MG was used to isolate a cDNA clone encoding epitopes present on a cytoplasmic polypeptide of apparent $M_{\mathrm{r}} 250,000$ (gravin). This reactivity was observed in $31 \%$ of MG patients, and apart from a single patient with rheumatoid arthritis, was not detected in sera from patients with several other autoimmune diseases. Gravin was localized to the cytoplasmic cortical regions of cultured cells in a trabecular pattern, suggesting it may be part of the cortical cytoskeleton. Moreover, gravin was expressed by several adherent cultured cells, but not by cells of the peripheral blood or by nonadherent U937 or HEL cells. In the latter case, PMA-stimulated differentiation was associated with increased cellular 
1 CGACTGTCAGGCAAAATCGACACCAGTGATAGTATCTGCTACTACCAAGAAAGGCTTAAG $\begin{array}{llllllllllllllllllll}D & \mathrm{C} & \mathrm{Q} & \mathrm{A} & \mathrm{K} & \mathrm{S} & \mathrm{T} & \mathrm{P} & \mathrm{V} & \mathrm{I} & \mathrm{V} & \mathrm{S} & \mathrm{A} & \mathrm{T} & \mathrm{T} & \mathrm{K} & \mathrm{K} & \mathrm{G} & \mathrm{L} & \mathrm{S}\end{array}$

61 TTCCGACCTGGAAGGAGAGAAAACCACATCACTGAAGTGGAAGTCAGATGAAGTCGATGA

$\begin{array}{llllllllllllllllllll}S & D & L & E & G & E & K & T & T & S & L & K & W & K & S & D & E & V & D & E\end{array}$

121 GCAGGTTGCTTGCCAGGAGGTCAAAGTGAGTGTAGCAATTGAGGAGGATTTAGAGCCTGA

$\begin{array}{llllllllllllllllllll}\mathrm{Q} & \mathrm{V} & \mathrm{A} & \mathrm{C} & \mathrm{Q} & \mathrm{E} & \mathrm{V} & \mathrm{K} & \mathrm{V} & \mathrm{S} & \mathrm{V} & \mathrm{A} & \mathrm{I} & \mathrm{E} & \mathrm{E} & \mathrm{D} & \mathrm{L} & \mathrm{E} & \mathrm{P} & \mathrm{E}\end{array}$

181 AAATGGGATTTTGGAACTTGAGACCAAAAGCAGTAAACTTGTCCAAAACATCATCCAGAC $\begin{array}{lllllllllllllllllllll}N & G & I & L & E & L & E & T & K & S & S & K & L & V & Q & N & I & I & Q & T\end{array}$

241 AGCCGTTGACCAGTTTGTACGTACAGAAGAAACAGCCACCGAAATGTTGACGTCTGAGTT $\begin{array}{llllllllllllllllllll}A & V & D & Q & F & V & R & T & E & E & T & A & T & E & M & L & T & S & E & L\end{array}$

301 ACAGACACAAGCTCACATGATAAAAGCTGACAGCCAGGACGCTGGACAGGAAACGGAGAA $\begin{array}{llllllllllllllllllll}\mathrm{Q} & \mathrm{T} & \mathrm{Q} & \mathrm{A} & \mathrm{H} & \mathrm{M} & \mathrm{I} & \mathrm{K} & \mathrm{A} & \mathrm{D} & \mathrm{S} & \mathrm{Q} & \mathrm{D} & \mathrm{A} & \mathrm{G} & \mathrm{Q} & \mathrm{E} & \mathrm{T} & \mathrm{E} & \mathrm{K}\end{array}$

361 AGAAGGAGAGGAACCTCAGGCCTCTGCACAGGATGAAACACCAATTACTTCAGCCAAAGA $\begin{array}{llllllllllllllllllll}E & G & E & E & P & Q & A & S & A & Q & D & E & T & P & I & T & S & A & K & E\end{array}$

421 GGAGTCAGAGTCAACCGCAGTGGGACAAGCACATTCTGATATTTCCAAAGACATGAGTGA

$\begin{array}{llllllllllllllllllll}E & S & E & S & T & A & V & G & Q & A & H & S & D & I & S & K & D & M & S & E\end{array}$

481 AGCCTCAGAAAAGACCATGACTGTTGAGGTAGAAGGTTCCACTGTAAATGATCAGCAGCT $\begin{array}{llllllllllllllllllll}A & S & E & K & T & M & T & V & E & V & E & G & S & T & V & N & D & Q & Q & L\end{array}$

541 GGAAGAGGTCGTCCTCCCATCTGAGGAAGAGGGAGGTGGAGCTGGAACAAAGTCTGTGCC

$\begin{array}{lllllllllllllllllllll}E & E & V & V & L & P & S & E & E & E & G & G & G & A & G & T & K & S & V & P\end{array}$

601 AGAAGATGATGGTCATGCCTTGTTAGCAGAAAGAATAGAGAAGTCACTAGTTGAACCGAA $\begin{array}{llllllllllllllllllll}E & D & D & G & H & A & L & L & A & E & R & I & E & K & S & L & V & E & P & K\end{array}$

661 AGAAGATGAAAAAGGTGATGATGTTGATGACCCTGAAAACCAGAACTCAGCCCTGGCTGA $\begin{array}{llllllllllllllllllll}E & D & E & K & G & D & D & V & D & D & P & E & N & Q & N & S & A & L & A & D\end{array}$

721 TACTGATGCCTCAGGAGGCTTAACCAAAGAGTCCCCAGATACAAATGGACCAAAACAAAA $\begin{array}{llllllllllllllllllll}T & D & A & S & G & G & L & T & K & E & S & P & D & T & N & G & P & K & Q & K\end{array}$

781 AGAGAAGGAGGATGCCCAGGAAGTAGAATTGCAGGAAGGAAAAGTGCACAGTGAATCAGA $\begin{array}{llllllllllllllllllll}E & K & E & D & A & Q & E & V & E & L & Q & E & G & K & V & H & S & E & S & D\end{array}$

841 TAAAGCGATCACACCCCAAGCACAGGAGGAGTTACAGAAACAAGAGAGAGAATCTGCAAA $\begin{array}{llllllllllllllllllll}K & A & I & T & P & Q & A & Q & E & E & L & Q & K & Q & E & R & E & S & A & K\end{array}$

901 GTCAGAACTTACAGAATCTTAAAACATCATGCAGTTAAACTCATTGTCTGTTTGGAAGAC $\begin{array}{lllllll}S & E & L & \mathrm{~T} & \mathrm{E} & \mathrm{S}\end{array}$

961 CAGAATGTGAAGACAAGTAGTAGAAGAAAATGAATGCTGCTGCTGAGACTGAAGACCAGT

1021 ATTTCAGAACTTTGAGAATTGGAGAGCAGGCACATCAACTGATCTCATTTCTAGAGAGCC

1081 CCTGACAATCCTGAGGCTTCATCAGGAGCTAGAGCCATTTAACATTTCCTCTTTCCAAGA

1141 CCAACCTACAATTTTCCCTTGATAACCATATAAATTCTGATTTAAGGTCCTAAATTCTTA

1201 ACCTGGAACTGGAGTTGGCAATACCTAGTTCTGCTTCTGAAACTGGAGTATCATTCTTTA

1261 CATATTTATATGTATGTTTTAAGTAGTCCTCCTGTATCTATTGTATATTTTTTTCTTAAT

1321 GTTTAAGGAAATGTGCAGGATACTACATGCTTTTTGTATCACACAGTATATGATGGGGCA

1381 TGTGCCATAGTGCAGGCTTGGGGAGCTTTAAGCCTCAGTTATATAACCCACAAAAAACAG

1441 AGCCTCCTAGATGTAACATTCCTGATCAAGGTACAATTCTTTAAAATTCACTAATGATTG

1501 AGGTCCATATTTAGTGGTACTCTGAAATTGGTCACTTTCCTATTACACGGAGTGTGCCAA

1561 AACTAAAAAGCATTTTGAAACATACAGAATGTTCTATTGTCATTGGGAAATTTTGCTTTC

1621 TAACCCAGTGGAGGTTAGAAAGAAGTTATATTCTGGTAGCAAATTAACTTTACATCCTTT

1681 TTCCTACTTGTTATGGTTGTTTGGACCGATAAGTGTGCTTAATCCTGAGGCAAAGTAGTG

1741 AATATGTTTTATATGTTATGAAGAAAAGAATTGTTGTAAGTTTTTGATTCTACTCTTATA

1801 TGCTGGACTGCATTCACACATGGCATGAAATAAGTCAGGTTCTTTACAAATGGTATTTTG

1861 ATAGATACTGGATTGTGTTTGTGCCATATTTGTGCCATTCCTTTAAGAACAATGTTGCAA

1921 CACATTCATTTGGATAAGTTGTGATTTGACGACTGATTTAAATAAAATATTTGCTTCACT

1981 TAAAAAAAAAAA 1993

1140

1200

1260

1320

1380

1440

1500

1560

1620

1680

1740

1800

1860

1920

1980

Figure 8 . Sequence of the $\lambda 15$ insert. The 1993-bp insert which in the second reading frame is in frame with the linkers used in library construction is shown with the translated 306 residue predicted protein sequence below. The polyadenylation signal is underlined.

content of gravin. Endothelial cell mRNAs of 6.7 and $8.4 \mathrm{~kb}$ hybridized with cDNA clone, but were not detected in two cells that fail to express the protein. The sequence of the clone indicated that it coded for a highly acidic region containing the carboxyl terminus of the polypeptide and that neither protein nor nucleotide sequences had been entered into standard data- bases as of March, 1992. Thus, an apparently novel component of the cytoplasm has been identified as an additional antigenic target in certain patients with MG. It is unclear at the present time why autoantibodies to gravin should develop in MG, but these patients often form antibodies to cytoskeletal proteins such as alpha actinin (5), vinculin, and filamin (6), and a 

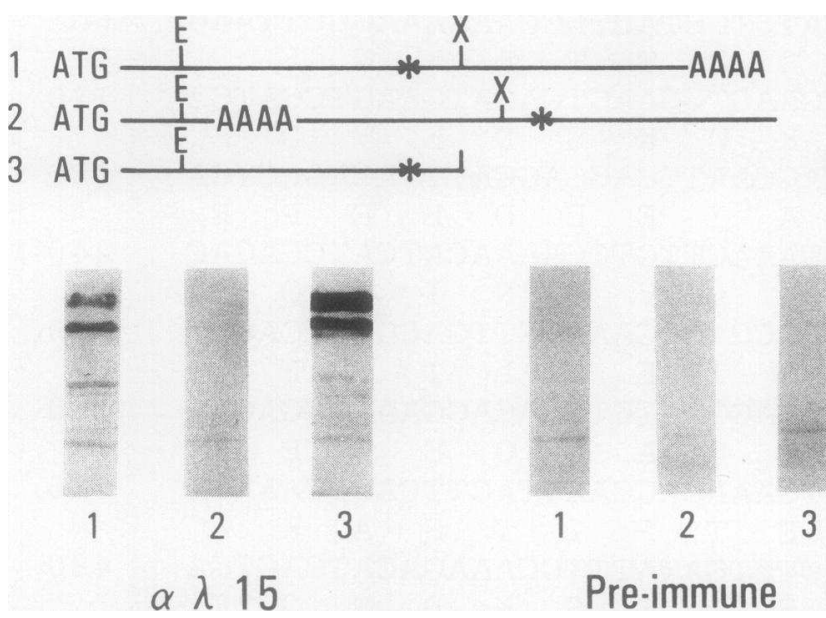

Figure 9. Expression of $\lambda 15$ in the plasmid Bluescript vector. The $\lambda 15$ insert was cloned into the $\operatorname{EcoRI}(E)$ site of Bluescript $\mathrm{KS}$ (Vector Laboratories) in frame with the initiation codon of $\beta$-galactosidase which is $104 \mathrm{bp}$ upstream from the EcoRI site (construct 1 ). The same insert was also cloned in the reverse orientation (construct 2). Deletion of the 917-bp end of construct 1 was achieved by restriction at the indicated $\mathrm{XbaI}(X)$ site (construct 3). 2-ml cultures of $E$. coli DH5 bearing each of these plasmids were grown in the presence of IPTG and lysed as suggested by the supplier (Stratagene Inc.) and the lysates analyzed by immunoblotting as described in Fig. 1 .

recent study has described reactivity with a $320-\mathrm{kD}$ sarcoplasmic reticulum protein (43). Antibodies to filamin and vinculin have been reported to occur in $97 \%$ and $30 \%$ of myasthenics, respectively (6). Like gravin, titers of these antibodies do not correlate with anti-acetylcholine receptor antibody levels (6). Detailed clinical studies will be necessary to determine the relationship, if any, of antigravin antibodies with the clinical features, thymic pathology, and course of MG.

It seems likely that gravin is encoded by the cDNAs isolated here. First, polyclonal antibodies raised against recombinant fusion protein in two rabbits and antibodies affinity-purified on the fusion protein reacted with gravin on crude cell extracts, while reactivity was blocked by absorption of rabbit antisera with fusion protein. Second, serum from patients with myasthenia gravis reacted with both the insert-coded polypeptide and native $250-\mathrm{kD}$ protein. Third, the mRNA species identified by Northern blotting with the cDNA is sufficient to encode a polypeptide the size of gravin. Fourth, the mRNa encoding the putative protein showed the same cell type-specific expression as gravin on Northern blots.

The meshwork staining of the cytoplasm and its peripheral extensions observed for gravin suggests that it is present in the cell cortex. It is noteworthy that several of the cytoskeletal proteins recognized by MG sera are components of the cortical cytoskeleton. Nevertheless, immunologic analysis indicates that gravin is distinct from actin binding protein (filamin) and nonerythroid spectrin (fodrin) which also localize to this region $(34,35)$. Since MG does not, in most cases (1), appear to be due to molecular mimicry, it has been suggested that the response is driven by antigens contained in the acetylcholine receptor and its associated cytoskeletal anchor. The site at which immunization occurs has not been definitely established, although the thymus (44) has been implicated. In view of the cell type-specific expression of gravin, it may be of value to investigate its tissue localization in vivo in relation to the acetylcholine receptor.

Gravin was expressed in a cell type-specific and regulatable manner and appears to be a component of the cell cortex. It was particularly noteworthy that the cells which adhered well in culture and form stress fibers possessed this protein. Since the distribution of stress fibers in endothelial cells is modulated by fluid shear (45-47) and cytokines (48), it will be of interest to examine the effects of these factors on gravin biosynthesis and distribution in endothelium.

\section{Acknowledgments}

We gratefully acknowledge Drs. Paul Schimmel and Ralph Nachman who suggested the name "gravin." Drs. Richard McPherson and Marge Seybold provided myasthenic patient sera and stimulating and helpful discussions. We also acknowledge the able secretarial support of Lynn LaCivita and Mary Brown.

This work was supported in part by a National Health and Medical Research Council Neil Hamilton Fairley Fellowship, and the D.E.V. Staff Research Fellowship in Rheumatology. Supported by National Institutes of Health grants HL-16411 and AR-27214. This is manuscript No. 5285 from the Department of Immunology of the Research Institute of Scripps Clinic.

\section{References}

1. Lindstrom, J. 1985. Immunobiology of myasthenia gravis, experimental autoimmune myasthenia gravis, and Lambert-Eaton syndrome. Annu. Rev. Immunol. 3:109-131.

2. Vetters, J. M. 1965. Immunofluorescence staining patterns in skeletal muscle using serum of myasthenic patients and normal controls. Immunology. 9:9395.

3. Strauss, A. J. L., and P. G. Kemp, Jr. 1967. Serum autoantibodies in myasthenia gravis and thymoma: selective affinity for 1-bands of striated muscle as a guide to identification of antigen(s). J. Immunol. 99:945-953.

4. Peers, J., B. L. McDonald, and R. L. Dawkins. 1977. The reactivity of the antistriational antibodies associated with thymoma and myasthenia gravis. Clin. Exp. Immunol. 27:66-73.

5. Williams, C. L., and V. A. Lennon. 1986. Thymic B lymphocyte clones from patients with myasthenia gravis secrete monoclonal striational autoantibodies reacting with myosin, alpha actinin, or actin. J. Exp. Med. 164:1043-1059.

6. Yamamoto, T., T. Sato, and H. Sugita. 1987. Antifilamin, antivinculin, and antitropomyosin antibodies in myasthenia gravis. Neurology. 37:1329-1333.

7. Bloch, R. J., and Z. W. Hall. 1983. Cytoskeletal components of the vertebrate neuromuscular junction: vinculin, a-actinin, and filamin. J. Cell Biol. 97:217-223.

8. Fujinami, R. S., and M. B. Oldstone. 1985. Amino acid homology between the encephalitogenic site of myelin basic protein and virus: mechanism for autoimmunity. Science (Wash. DC). 230:1043-1045.

9. Young, R. A., and R. W. Davis. 1983. Efficient isolation of genes by using antibody probes. Proc. Natl. Acad. Sci. USA. 80:1194-1198.

10. Earnshaw, W. C., K. F. Sullivan, P. S. Machlin, C. A. Cooke, D. A. Kaiser, T. D. Pollard, N. F. Rothfield, and D. W. Cleveland. 1987. Molecular cloning of cDNA for CENP-B, the major human cetromere autoantigen. J. Cell Biol. 104:817-829.

11. Theissen, H., R. Etzerodt, R. Reuter, C. Schneider, F. Lottspeich, P. Argos, R. Luhrmann, and L. Philipson. 1986. Cloning of the human cDNA for the U1 RNA-associated 70k protein. EMBO (Eur. Mol. Biol. Organ.) J. 5:32093217.

12. Haabets, W. J., P. T. G. Sillekens, M. H. Hoet, J. A. Schalken, A. J. M. Roebroek, J. A. M. Leunissen, W. J. M. van den Ven, and W. J. van Venrooij. 1987. Analysis of a cDNA clone expressing a human autoimmune antigen: full length sequence of the $\mathrm{U} 2$ small nuclear RNA-associated B" antigen. Proc. Natl. Acad. Sci. USA. 84:2421-2425.

13. Sillekens, P. T. G., W. J. Habets, R. P. Beijer, and W. J. van Venrooij. 1987. cDNA cloning of the human U1 snRNA-associated protein: extensive homology between U1 and U2 snRNP-specific proteins. EMBO (Eur. Mol. Biol. Organ.) J. 6:3841-3848.

14. Dropcho, E. J., Y.-T. Chen, J. B. Posner, and L. J. Old. 1987. Cloning of a brain protein identified by autoantibodies from a patient with paraneoplastic cerbellar degeneration. Proc. Natl. Acad. Sci. USA. 84:4552-4556. 
15. Pollard, T. D. 1984. Actin-binding protein evolution. Nature (Lond.). 312:403.

16. Baron, M. D., M. D. Davison, P. Jones, and D. R. Critchley. 1987. The sequence of chicken alpha-actinin reveals homologies to spectrin and calmodulin. J. Biol. Chem. 262:17623-17629.

17. Sadler, J. E., B. B. Shelton-Inloes, J. M. Sorace, J. M. Harlan, K. Titani, and E. W. Davie. 1985. Cloning and characterization of two cDNAs coding for human von Willebrand factor. Proc. Natl. Acad. Sci. USA. 82:6394-6398.

18. Loftus, J. C., E. F. Plow, A. L. Frelinger III, S. E. D'Souza, D. Dixzon, J. Lacy, J. Sorge, and M. H. Ginsberg. 1987. Molecular cloning and chemical synthesis of a region of platelet GPIIb involved in adhesive function. Proc. Natl. Acad. Sci. USA. 840:7114-7118.

19. Anderson, M. J., V. L. Woods, P. Tani, J. Lindstrom, D. Schmidt, and R. McMillan. 1984. Autoantibodies to platelet glycoprotein IIb/IIla and to the acetylcholine receptor in a patient with chronic idiopathic thrombocytopenic purpura and myasthenia gravis. Ann. Intern. Med. 100:829-831.

20. Laemmli, U. K. 1970. Cleavage of structural proteins during the assembly of the head of bacteriophage T4. Nature (Lond.). 227:680-685.

21. Poncz, M., D. Solowiejczyk, M. Ballantine, E. Schwartz, and S. Surrey. 1982. "Nonrandom" DNA sequence analysis in bacteriophage M13 by the dideoxy chain-termination method. Proc. Natl. Acad. Sci. USA. 79:4298-4302.

22. Sanger, F., S. Nicklen, and R. Coulson. 1977. DNA sequencing with chain terminating inhibitors. Proc. Natl. Acad. Sci. USA. 74:5463-5467.

23. Tabor, S., and C. C. Richardson. 1987. DNA sequencing analysis with a modified bacteriophage T7 DNA polymerase. Proc. Natl. Acad. Sci. USA. 84:4767-4771.

24. Devereux, J., P. Haeberli, and O. Smithies. 1984. A comprehensive set of sequence analysis programs for the VAX. Nucleic Acids Res. 12:387-395.

25. Weinberger, C., S. M. Hollenberg, E. S. Ong, J. Harmon, S. T. Brower, J. Cidlowski, E. B. Thompson, M. G. Rosenfeld, and R. M. Evans. 1985. Identification of human glucocorticoid receptor complementary DNA clones by epitope selection. Science (Wash. DC). 228:740-742.

26. Ginsberg, M. H., L. Taylor, and R. G. Painter. 1980. The mechanism of thrombin-induced platelet factor 4 secretion. Blood. 55:661-668.

27. Henson, P. M., and Z. G. Oades. 1975. Stimulation of human neutrophils by soluble and insoluble immunoglobin aggregates. Secretion of granule constituents and increased oxidation of glucose. J. Clin. Invest. 56:1053-1061.

28. Boyum, A. 1968. Ficoll hypaque method for separating mononuclear cells and granulocytes from human blood. Scand. J. Clin. Lab. Invest. 21 (Suppl.):7778.

29. Levin, E. G. 1983. Latent tissue plasminogen activator produced by human endothelial cells in culture: evidence for an enzyme-inhibitor complex. Proc. Natl. Acad. Sci. USA. 80:6804-6808.

30. Plow, E. F., J. Loftus, E. Levin, D. Fair, D. Dixon, J. Forsyth, and M. H. Ginsberg. 1986. Immunologic relationship between platelet membrane glycoprotein GPIIb/IIa and cell surface moleculartes expressed by a variety of cells. Proc. Natl. Acad. Sci. USA. 83:6002-6006.

31. Maniatis, T., E. F. Fritsch, and J. Sambrook. 1982. Molecular Cloning: A Laboratory Manual. Cold Spring Harbor Laboratory Press, Cold Spring Harbor, NY.
32. Stuber, D., H. Matile, and G. Garotta. 1990. System for high-level production in Escherichia coli and rapid purification of recombinant proteins. In Immunological Methods. Vol. IV. I. Lef kovits and B. Pernis, editors. Academic Press, New York. 121-152.

33. Papayannopaulou, T., B. Nakamto, T. Yokochi, A. Chait, and R. Kannagi. 1983. Human erythroleukemia cell line (HEL) undergoes a drastic macrophage-like shift with TPA. Blood. 62:832-845.

34. Stendahl, O. I., J. H. Hartwig, E. A. Brotschi, and T. P. Stossel. 1980. Distribution of actin-binding protein and myosin in macrophages during spreading and phagocytosis. J. Cell Biol. 84:215-224.

35. Pratt, B. M., A. S. Harris, J. S. Morrow, and J. A. Madri. 1984. Mechanisms of cytoskeletal regulation. Modulation of aortic endothelial cell spectrin by the extracellular matrix. Am. J. Pathol. 117:349-354.

36. Fox, J. E. B. 1986. Platelet contractile proteins. In Biochemistry of Platelets. D. R. Phillips and M. A. Schuman, editors. Academic Press, New York. $115-157$.

37. Davies, G. E., and C. M. Cohen. 1985. Platelets contain proteins immunologically related to red cell spectrin and protein 4.1. Blood. 65:52-59.

38. O'Halloran, T., M. C. Beckerle, and K. Burridge. 1985. Identification of talin as a major cytoplasmic protein implicated in platelet activation. Nature (Lond.). 317:449-451.

39. Chou, P. Y., and G. D. Fasman. 1978. Prediction of the secondary structure of proteins from their amino acid sequence. Adv. Enzymol. Relat. Areas Mol. Biol. 47:45-148.

40. Jameson, B. A., and H. Wolf. 1987. Predicting antigenicity from protein primary structure: a new algorithm for the prediction of antigenic sites. Comput. Appl. Biosci. 4:187-191.

41. Geisler, N., U. Plessmann, and K. Weber. 1985. The complete amino acid sequence of the major mammalian neurofilament protein (NF-L). FEBS (Fed. Eur. Biochem. Soc.) Lett. 182:475-478.

42. George, D. G., B. C. Orcutt, M. O. Dayhoff, and W. C. Barker. 1986. Relate: program for detecting distant relationships. Protein Identification Report REL-0286. National Biomedical Research Foundation.

43. Mygland, A., O. B. Tysnes, J. A. Aarli, P. R. Flood, and N. E. Gilhus. 1991. Myathenia gravis patients with a thymoma have antibodies against a sarcoplasmic reticulum protein. J. Autoimmun. 4:36a. (Abstr.).

44. Engel, W. K., J. L. Trotter, D. E. McFarlin, and C. L. McIntosh. 1977. Thymic epithelial cell contains acetylcholine receptor. Lancet. 1310-1311.

45. Gabbiani, G., F. Gabbiani, D. Lombardi, and S. M. Schwartz. 1983. Organization of actin cytoskeleton in normal and regenerating arterial endothelial cells. Proc. Natl. Acad. Sci. USA. 80:2361-2364.

46. Wong, A. J., T. D. Pollard, and I. M. Herman. 1983. Actin filament stress fibers in vascular endothelial cells in vivo. Science (Wash. DC). 219:867-869.

47. White, G. E., and K. Fujiwara. 1986. Expression and intracellular distribution of stress fibers in aortic endothelium. J. Cell Biol. 103:63-70.

48. Stolpen, A. H., E. C. Guinan, W. Fiers, and J. S. Pober. 1986. Recombinant tumor necrosis factor and immune interferon act singly and in combination to reorganize human vascular endothelial cell monolayers. Am. J. Pathol. 123:16-24. 